\title{
Erratum to: The Human Capital Imperative
}

\author{
Alan Coppin
}

\section{Erratum to:}

Chapter 17 in: A. Coppin, Not-For-Profits' Leaders Insights, https://doi.org/10.1007/978-3-319-49121-9_17

Chapter 21 in: A. Coppin, The Human Capital Metrics, https://doi.org/10.1007/978-3-319-49121-9_21

The original version of the book was inadvertently published with mistakes in the Table of Contents and chapter headings. The title of chapters 17 and 21, Part IV and Part V have now been corrected as explained below.

Chapter 17 title should be "Not-For-Profit Leader Insights" instead of "Not-For-Profits' Leaders Insights".

Part IV title should be "Human Capital Analytics" instead of "Institutes And Associations".

Chapter 21 title should be "Metrics" instead of "The Human Capital Metrics".

Part V title should be "Conclusion" instead of "Human Capital Analytics".

The updated online version of these chapters can be found at https://doi.org/10.1007/978-3-319-49121-9_17 https://doi.org/10.1007/978-3-319-49121-9_21

(C) The Author(s) 2017 